\title{
Debates políticos na internet: a perspectiva da conversação civil
}

\author{
Francisco Paulo Jamil Almeida Marques
}

Universidade Federal da Bahia

\begin{abstract}
Resumo
Este artigo examina teoricamente algumas das dimensões da interface entre democracia e novas tecnologias digitais de comunicação e informação. Começando por um reconhecimento do estado da arte acerca da categoria "esfera pública", a proposta é avaliar as possibilidades de estabelecimento de uma versão virtual deste espaço discursivo. Para isso, procura-se apresentar os discursos a favor e os discursos contrários a plausibilidade do conceito de esfera pública virtual. Tais argumentos servem para fundamentar a proposta aqui defendida de esfera pública virtual enquanto conversação civil, ou seja, os debates desenvolvidos em listas de discussão e fóruns on-line abertos a qualquer usuário atuam de modo mais eficaz como espaço destinado à formação complementar de opiniões do que como um espaço decisório por excelência. A forma democrática de governo tem, assim, nas redes telemáticas, um canal alternativo para fomentar a participação dos cidadãos.
\end{abstract}

Palavras-chave: democracia, esfera pública, opinião pública, internet, comunicação política

\begin{abstract}
This article examines specific questions about democracy and digital technologies of communication. The paper begins presenting the notion of public sphere as a guide to evaluate the possibilities of a virtual version of this discursive space. Then, it discusses certain arguments offered by authors for and against the notion of virtual public sphere. Such arguments give the necessary background to develop the proposal of virtual public sphere neither as a genuine discursive space nor as a space that refuses the requisites of a normative public sphere. In other words, this paper defends that most of the discursive spaces found in the internet act in a more efficient way as places dedicated to what is called civic conversation. Most of the debates in lists and online forums serve as a way to improve the given and take of opinions. The conclusion considers that democracy has through the internet an alternative way to foster citizen's participation.
\end{abstract}

Key words: democracy, public sphere, public opinion, internet, political communication 


\section{Introdução}

Não são poucas as assertivas que atestam uma revitalização da democracia e de suas instituições com o advento das novas tecnologias de comunicação e informação, mais destacadamente a internet. Dentre as teses mais populares, estão algumas razoavelmente plausíveis, mas não suficientemente investigadas, como a de que o Estado tornar-se-ia próximo do cidadão por oferecer serviços de modo conveniente e ágil, e por ganhar transparência (FERGUSON, 2002, p. 104; CEBRIÁN, 1999, p. 17) ${ }^{1}$. Há ainda proposições mais polêmicas que sustentam que, com a internet, decisivamente o caráter de oligopólio que marca a comunicação massiva contemporânea seria enfraquecido, no qual se protegeriam os grandes conglomerados de informação e entretenimento (MORAES, 2001; GUIDI, 2002, p. 183).

Para asseverar a euforia com a qual o tema muitas vezes é tratado, basta associar "internet" à "esfera pública"2 (um dos principais fundamentos da democracia contemporânea) nos formulários dos diversos buscadores disponíveis na rede e constatar que centenas de referências deslizam pela tela em poucos segundos.

Em verdade, seria pouco inteligente descartar toda a gama de possibilidades democráticas abertas por este sistema de comunicação digital, mais plural, dinâmico e que realça o oferecimento dos vários pontos de vista. Como defende Daniel Bougnoux, todavia, "(...) nossas relações técnicas estão necessariamente engestadas em relações pragmáticas que as precedem e as dirigem. Está-se de acordo, hoje, ao dizer que se a ferramenta autoriza, ela raramente determina" (BOUGNOUX, 1999, p. 107). Em outros termos, se os benefícios são inegáveis, torna-se forçoso verificar, por outro lado, as características relativas à apreensão sócio-cultural de tais aparatos tecnológicos que permeiam o hodierno, para, posteriormente, examinar sua eficácia e maneiras de inserção, por exemplo, no jogo político ${ }^{3}$. O certo é que nem todas as observações e investigações sobre o tema democracia devem ser reconsideradas a partir do espaço de fluxos - expressão empregada por Castells (1999).

\footnotetext{
1 Também sobre a questão da transparência, identificada com o princípio de accountability (ou responsabilização), trabalhado por Gutmann e Thompson (1996, 1999) e Maia (2002b), a Controladoria Geral da União tornou disponível, desde novembro de 2004, o "Portal da Transparência" (http://www.portaldatransparencia.gov.br/), que permite verificar os repasses feitos pelo Governo Federal aos estados e municípios.

2 Ressalte-se que o termo "esfera pública", conforme aqui empregado, se refere, fundamentalmente, ao tratamento de temas políticos.

${ }^{3}$ Conforme reflexão de Hubertus Buchstein: "In addition, the use of the internet has to be carefully situated within the context of already existing democratic institutions. And finally, a chance of perspective is necessary. This perspective reaffirms democracy and not technology as the starting point of any reform agenda" (BUCHSTEIN, 1997, p. 260).
} 
Neste contexto, toma-se a tarefa de refletir sobre algumas das implicações geradas pelas novas tecnologias de comunicação no campo da política. Obviamente, um artigo, por suas limitações espaciais, não pode apresentar como pretensão o tratamento geral e aprofundado de todas as dimensões políticas que a internet abrange. Deve-se atentar para o fato de que, apesar das redes digitais consistirem de uma plataforma de comunicação usada com maior vigor apenas recentemente, já são diversas as suas reverberações nos diferentes domínios da política (inúmeras modalidades de ativismo, comunicação político-partidária, voto on-line, comunicação governo-cidadão, dentre outras questões que vêm, inclusive, tornando-se agenda de pesquisa). Este escrito, assim, tem como meta se dedicar à discussão mais específica de uma destas classes de fenômenos, a saber, a noção de esfera pública virtual, expondo os aspectos mais candentes relativos aos debates públicos desenvolvidos nas redes telemáticas ${ }^{4}$. O seguinte itinerário para alcançar tal fim é o seguinte: (1) uma breve explanação dos fatores que convergem para a necessidade de discussão do conceito de esfera pública virtual; (2) uma fundamentação do que é comumente compreendido por esfera pública virtual, a partir da exposição dos discursos contra e dos discursos a favor quanto à procedência deste conceito; e, por fim, (3) a defesa da compreensão da noção de esfera pública virtual enquanto espaço preferencialmente propício à realização do que se chama de conversação civil. Conclui-se com a proposição de que os espaços discursivos digitais funcionam de modo mais adequado como ferramentas de apoio para o aperfeiçoamento das instituições democráticas (sem abrir mão delas), possibilitando, por exemplo, a criação de uma gama de artifícios com o objetivo de fomentar a participação dos cidadãos.

\section{A aproximação entre as categorias "esfera pública" e "esfera pública virtual"}

A internet ${ }^{5}$, em princípio, funciona como uma rede que permite aos seus usuários o contato e a difusão de informações sem necessariamente pedirem

\footnotetext{
${ }^{4}$ Ressalte-se que a intenção primordial não é esclarecer a compreensão do conceito de esfera pública na íntegra, seu histórico, autores principais e compreensões diversas. Na verdade, tal tarefa seria, no mínimo, repetitiva, visto que o tema foi consistentemente trabalhado em diversas outras referências. Pode-se consultar Gomes (1998, 1999 e 2001a) e Maia (2001 e 2002a).

${ }^{5}$ Wilson Gomes, em texto datado de 2001, no intento de evitar distorções em relação ao entendimento do fenômeno da comunicação digital, atenta para a necessidade de se fazer uma reflexão sobre o que se vem chamando de internet. $O$ artifício utilizado permite cessar certas discordâncias teóricas, pois toma a internet a partir de três dimensões: (1) como uma rede de computadores estabelecida mundialmente, isto é, uma infra-estrutura (hardware) que possibilita uma volumosa circulação de informações; (2) como uma biblioteca gigantesca de conteúdos, com informações disponíveis a qualquer terminal sobre diversos temas, e que a cada dia cresce em quantidade, permitindo uma reprodução rápida, além do registro em máquinas privadas; (3) a terceira dimensão identificada estaria nas formas de interação
} 
permissão aos grupos mediáticos já consolidados. Ela se apresenta como um espaço apto a atender demandas individuais, onde cada um busca a informação que deseja, podendo modificá-la ou adicionar suas considerações para uma posterior publicação, sem grandes dificuldades ou custos.

Graças a estes aspectos, a internet é tomada, por diferentes autores, como uma espécie de "revigorante" da esfera pública política argumentativa, pois (1) concede oportunidade de expressão a vozes marginais, sem as barreiras impostas pela censura governamental ou pelos interesses das indústrias do entretenimento e da informação (MITRA, 2001, p. 45), e porque (2) oferece a chance da reciprocidade discursiva advinda da esfera civil (ALLAN, 2003).

A superação de barreiras como o espaço (a comunicação digital não leva em conta as fronteiras dos países) abre caminho para a participação de usuários em diversos contextos geográficos. O direito de uso da palavra, a isegoria, conforme chamavam os atenienses, o poder falar em "assembléia", daria à internet, de acordo com as referências acima indicadas, a propriedade fundamental para o estabelecimento de um espaço argumentativo digital, o que tornaria o computador um meio de comunicação diferenciado em termos políticos.

A partir do momento em que favorecem a troca de experiências e conteúdos, as redes telemáticas também atuam, pelo menos em potência, como ambiente propício ao diálogo e ao entendimento. Falando-se em termos ideais, isso traria aos cidadãos interessados a possibilidade de, novamente, possuir certa influência nos rumos da esfera pública política, encontrando, comodamente, outros cidadãos para discutir questões de interesse público ${ }^{6}$. A metáfora da rede como artifício ou arma a

possibilitadas a partir da conexão e do acesso ao mundo de informações; a troca de mensagens particulares, ou a participação em listas de discussão, as salas e programas de bate-papo, onde seriam problematizadas emissão e recepção a partir de "vínculos interpessoais" (GOMES, 2001b). Para fins de análise acerca da reverberação no campo político, deve-se assinalar que apenas as duas últimas dimensões podem ser realmente consideradas nos estudos das arenas discursivas digitais.

${ }^{6}$ A pouca porosidade da esfera pública à influência do cidadão comum é um dos pilares da mudança estrutural defendida por Habermas (1984). Para Habermas, ao possibilitar a associação de homens privados em agremiações específicas, o surgimento dos partidos faz com que os cidadãos particulares não mais se coloquem para debater suas próprias idéias da forma vivaz que acontecia antes, mas, geralmente, estejam prontos a aderir às idéias de seus correligionários, prontos a negar as iniciativas dos oponentes, por melhores que elas sejam, por mais que esta atitude vá de encontro às suas sinceras reflexões pessoais. A discussão sobre as formas de comando político de um Estado passaria, desde então, no dizer de Habermas, a ser elitizada em partidos antagônicos que se organizam para além da instância local das comunidades, estabelecendo uma estrutura burocrática de funcionamento que visa manter seus signatários sob sintonia ideológica. Isto quer dizer que, cada vez mais, as vontades deixam de ser formadas no confronto entre as opiniões dos indivíduos, de um público esclarecido, para permanecerem sob jugo de poucos dirigentes que, com a conivência dos demais arregimentados, estabelecem as diretrizes e projetos a serem implantados a partir do momento em que seus partidos tencionam chegar ao poder. A opinião pública, igualmente, deixa de ser resultado de um debate racional entre desprovidos de investidura para ganhar feições institucionais. 
ser utilizada pelos cidadãos na busca por um "novo pacto democrático" (LÉVY, 1998; ANTOUN, 2002) se liga à noção de resgate de uma cidadania perdida pelo afastamento entre esfera política (com o poder decisório, composta pelos representantes eleitos) e esfera civil (mandante, mas não mandatária), e pela especialização excessiva relativa à gerência da coisa pública, o que inviabiliza uma maior participação popular?.

Independente de admitir, por ora, se tais modificações ocorrem ou não, e em que gradiente ocorrem, o fato é que as novas tecnologias de comunicação e informação vêm tornar mais instável a discussão conceitual sobre a categoria esfera pública, essencial para a compreensão da relação entre Estado e esfera civil nas sociedades democráticas contemporâneas.

Deve-se dizer, em um primeiro momento, que muito da confusão sobre se a internet pode ou não ser tomada como espaço argumentativo com vistas a influenciar a deliberação (ou mesmo servir como espaço deliberativo) tem relação com o entendimento pouco eficaz da própria categoria esfera pública.

De forma sucinta, pode-se compreender a noção esfera pública a partir de três ângulos (GOMES, 1999): (a) o debate deliberativo, essencial à democracia, que pode ser exemplificado através das argumentações apresentadas nas casas parlamentares, ou mesmo ligado a assuntos de um grupo particular, como uma associação de moradores ou acionistas de uma empresa, com o objetivo de definir políticas; (b) o debate não-deliberativo, na maioria dos casos com fins informativos, com a intenção de fornecer aos interessados uma maior capacidade de reflexão dos prós e contras de determinada matéria (ou apenas mantê-los a par do assunto). Este debate também pode ser classificado como conversação civil, ocorrendo em situações cotidianas, sem a marca da formalidade. Por último, a esfera pública pode consistir de uma (c) esfera de exposição ou visibilidade pública, quer dizer, quando não há necessariamente uma realização dialógica entre quem emite e quem recebe determinado conteúdo, ocorrendo a exposição, sobretudo através dos mass media, de materiais acerca do que deverá habitar os setores deliberativos.

Esta tipologia acerca dos debates parece manter proximidade com as compreensões mais recentes de Habermas, sobretudo aquela evidenciada em seu livro Direito e democracia (2003). De acordo com determinado trecho do livro:

\footnotetext{
${ }^{7}$ A esperança depositada no alcance de uma democracia mais participativa (BARBER, 1984) influencia, sem dúvida, as impressões e análises acerca das relações entre internet e esfera pública, conforme o argumento a seguir: "A impressão que tenho (...) é que insistência sobre a conexão entre internet e esfera pública apóia-se numa tese sobre a natureza da democracia e sobre a participação popular na esfera da decisão política. Assegurando-se a internet como esfera pública, em suma, assegura-se a idéia de que ainda há formas e meios para a participação popular na vida pública, assegura-se que a internet produz e promove novas e promissoras formas de deliberação política por parte da esfera civil" (GOMES, 2004).
} 
"Em sociedades complexas, a esfera pública forma uma estrutura intermediária que faz a mediação entre o sistema político, de um lado, e os setores privados do mundo da vida e sistemas de ação especializados em termos de funções, de outro lado. Ela representa uma rede supercomplexa que se ramifica espacialmente num sem número de arenas internacionais, nacionais, regionais, comunais e subculturais, que se sobrepõem umas às outras (...)" (HABERMAS, 2003, p. 107).

É assim que Habermas começa a admitir a formação de outras modalidades de esfera pública, deixando, de certa forma, o rígido tratamento dado ao conceito em seu livro de 1962, e já sob o impacto das diversas críticas advindas, sobretudo, da leitura norte-americana da obra Mudança estrutural na esfera pública (CALHOUN, 1992). Tal mudança de postura pode ser percebida quando detalha diferentes formas de esfera pública que agora reconhece:

“(...) esfera pública episódica (bares, cafés, encontros na rua), esfera pública da presença organizada (encontros de pais, público que freqüenta o teatro, concertos de rock, reuniões de partidos ou congressos de igrejas) e esfera pública abstrata, produzida pela mídia (leitores, ouvintes e espectadores singulares e espalhados globalmente). Apesar dessas diferenciações, as esferas públicas parciais, constituídas através da linguagem comum ordinária, são porosas, permitindo uma ligação entre elas" (HABERMAS, 2003, p. 107).

Apesar do autor ser acusado de esgarçar o conceito, a ponto de admitir que determinados debates frívolos sejam considerados uma legítima esfera pública, o que forçou a incorporação do adjetivo "política" à noção em questão, haveria, assim, de acordo com esta concepção, uma esfera pública de âmbito civil, isto é, um espaço discursivo não intimamente ligado ao plano institucional-parlamentar. Mesmo possuindo um caráter pouco organizado, informal e sem ordem temática pré-estabelecida, pode-se propor a existência, nestes termos, de espaços de debates não-deliberativos que conformam conversações civis ${ }^{8}$.

O reconhecimento da legitimidade deste espaço discursivo informal e espontâneo entra em sintonia com as tentativas empreendidas pela "periferia" social (termo que Habermas emprega para designar os que estão afastados do

\footnotetext{
8 Terminologia discutida no âmbito da disciplina Media e Política, Programa de Pós-Graduação em Comunicação e Cultura Contemporâneas (UFBA).
} 
poder institucional conferido aos representantes políticos e parlamentares) de "forçar" a discussão de determinados temas e oferecer novas interpretações a questões de interesse coletivo. Para o autor, “(...) a periferia consegue preencher essas expectativas fortes, na medida em que as redes de comunicação pública não institucionalizada possibilitam processos de formação de opinião mais ou menos espontâneos" (HABERMAS, 2003, p. 90).

Deve-se, assim, procurar reconhecer o valor dos espaços discursivos oferecidos aos cidadãos, por exemplo, através dos meios de comunicação de massa. Pelo que se já falou, a internet possui a capacidade de abrigar diversas destas arenas de discussão, pois se trata de uma rede de comunicação pública não necessariamente institucionalizada e, em muitas ocasiões, local que abriga a formação espontânea de opiniões.

A partir desta idéia, é importante, então, investigar até que ponto a abertura destas arenas no ambiente digital gera um efetivo poder político para os que se encontram na "periferia", pois uma maior efetividade (ou capacidade de poder algo) da soberania popular não se pode limitar aos debates; e permite que determinados parâmetros defendidos, por exemplo, por noções da democracia deliberativa (como a reciprocidade ou a busca pelo debate controvertido, e não apenas com aqueles com os quais já se tem afinidade ideológica) sejam atingidos (GUTMANN e THOMPSON, 2004; BOHMAN, 1996).

A tentativa dos próximos tópicos é procurar fundamentar a versão de esfera pública política enquanto conversação civil como aquela mais adequada à compreensão da maioria dos debates que ocorrem atualmente na internet, seja em listas de discussão, salas de bate-papo ou em fóruns públicos abrigados nos mais diferentes sítios.

A bem da verdade, em dada medida, a internet e os espaços discursivos abertos por este ambiente de interconexão poderiam dar asilo a todas as três compreensões de esfera pública acima enunciadas. Mas a hipótese deste trabalho é de que uma esfera pública virtual entendida como espaço deliberativo (no sentido decisório conferido às casas legislativas) de grandes questões nacionais ou como espaço de massiva visibilidade pública seria mais difícil de ser realizada em sua plenitude.

Se pensarmos na possibilidade de vislumbrar representantes políticos debatendo e decidindo através do uso de tecnologias digitais (o que já seria possível), não haveria grandes diferenças entre uma esfera pública parlamentar tradicional e uma esfera pública parlamentar virtual. Perderia sentido, assim, a euforia em torno da inauguração de uma esfera pública virtual, pois haveria apenas uma transposição de canal comunicativo que pouco representaria em termos de 
inclusão de atores à parte das decisões ${ }^{9}$. Já um debate mais ampliado entre os representantes políticos e todos os cidadãos interessados em interferir e sugerir também parece, de certa forma, inviável, graças a fatores como, por exemplo, a lei do tempo e dos números, citada por Dahl (2001)

Em outras palavras, não se deixa de reconhecer que as teorias elitistas da democracia, ao defenderem a delegação de poderes a indivíduos pretensamente mais capacitados e dedicados aos negócios públicos, possuem, sim, certa parcela de razão por evitar a adoção de modelos que defendem, por exemplo, uma participação direta de todos os interessados, através de plebiscitos. Mas, obviamente, deve-se pôr um limite a essa delegação de poderes.

Adicionalmente, não obstante as redes telemáticas difundirem-se rapidamente, ainda não podem ser consideradas a fonte primordial provedora de informação para a esfera civil. Nas palavras de Wolton (2001), a lógica da internet seria diferente da lógica dos meios "generalistas".

Graças a estas razões, parece mais plausível o funcionamento eficaz dos espaços digitais de discussão na perspectiva de uma conversação civil, de um espaço potencialmente vívido onde se gera discussão na tentativa de se conferir poder de influência aos atores da "periferia". Ou seja, os cidadãos com acesso ao computador em rede podem se reunir livremente para discutir qualquer tema e fazer quaisquer proposições sem constrangimentos, ainda que a efetividade deste tipo de ação seja, na maioria das ocasiões, de pequeno alcance.

\section{Sobre a viabilidade de uma esfera pública virtual}

As disputas teóricas em torno do tema "internet e esfera pública" tendem a se concentrar em dois pólos. Um primeiro conjunto de autores admite o funcionamento dos espaços discursivos digitais como esfera pública por excelência, pois as redes telemáticas atuariam como canal de expressão legítimo de vozes

\footnotetext{
9 Não se vai cogitar aqui a proposta de democracia direta através das redes telemáticas, dificilmente alcançável mesmo para os maiores defensores da proposta de democracia participativa.

10 Um dos cientistas políticos norte-americanos de maior relevância ao longo da segunda metade do século XX, Robert Dahl, reverbera de certa forma as idéias da teoria elitista quando, por exemplo, rechaça uma participação popular mais efetiva ao levar em consideração o fator "eficácia do sistema" [democrático] como categoria fundamental para se compreender as limitações em se instaurar uma participação civil efetiva. De acordo com sua argumentação: "A lei do tempo e dos números: quanto mais cidadãos uma unidade democrática contém, menos esses cidadãos podem participar diretamente das decisões do governo e mais eles têm de delegar a outros essa autoridade. (...) Contudo, se nossa meta é estabelecer um sistema democrático de governo que proporcione o maior terreno possível para tratar eficazmente dos problemas de maior importância para os cidadãos, então, em geral, a vantagem estará numa unidade de tal tamanho que será preciso um governo representativo. Este é o dilema da participação do cidadão versus a eficácia do sistema" (DAHL, 2001, p. 125).
} 
antes marginalizadas e como espaço de questionamento das visões produzidas num ambiente "refeudalizado". A confluência de informações ininterruptas e de usuários distantes no plano espacial-geográfico seriam, inclusive, vantagens adicionais trazidas pelo advento deste novo meio de comunicação, que é o computador conectado em rede.

Há, por outro lado, uma vertente mais cética quanto à eficácia das tecnologias digitais de comunicação para o aperfeiçoamento da democracia. Wolton (2001), por exemplo, considera a internet e suas arenas discursivas como algo pouco sério, um espaço onde predomina o caos e a experimentação adolescente. Além disso (e, aqui, uma objeção feita pelos autores que se filiam à corrente deliberativa da teoria democrática, como Buchstein e Witchstge), nada garante que, uma vez mostradas as armas e iniciada a contenda retórica, os cidadãos distantes fisicamente queiram se manifestar de acordo com regras mínimas de civilidade para produzir um debate frutífero ${ }^{11}$.

Entre estes dois pólos, há uma interpretação que vem ganhando maior espaço nas últimas publicações acadêmicas, talvez porque se constate que as novas tecnologias de comunicação modificam apenas alguns aspectos, e não a íntegra, de campos sociais tradicionalmente estabelecidos (como o comércio ou a política). Em outras palavras, esta terceira posição compreende a esfera pública virtual enquanto um complemento para uma melhor formação cívica, como um lugar de debates de naturezas distintas (uns mais sérios, outros nem tanto), mas sem maior viabilidade de se aliar à deliberação plena, à decisão efetiva quanto à implantação das políticas públicas. Novamente, aqui, procede-se o delineamento da concepção de esfera pública virtual, preferencialmente, como conversação civil. Os pressupostos de cada uma das vertentes acima delineadas são apresentados a seguir.

\footnotetext{
11 Não que os debates face a face sejam todos bem comportados, mas a tendência em se transgredir as regras de reciprocidade, por exemplo, é mais remota numa interação pessoal. Se o anonimato permite a expressão política de indivíduos tímidos ou que não podem se manifestar por pressões outras (de seus familiares ou dos chefes no trabalho), por outro lado, condiciona os entes do discurso a se tornarem, tendencialmente, menos confiáveis uns aos outros, ou menos confiáveis do que seriam se conversassem face a face: as linhas de um diálogo em bate-papo não permitem que se apreenda a entonação da voz, a reação de quem interage quando dado posicionamento é exposto. Além disso, a natureza escrita, e não falada (na maioria das vezes), destes debates pode limitar a capacidade argumentativa, pois não se escreve tão rápido quanto se fala; ou nem todos têm disposição integral em escrever um argumento por completo quando conversa na internet. São duas questões técnicas, é verdade, e que tendem a ser dissipadas dentro de alguns anos, mas ainda geram ressalvas para a qualidade do debate.
} 


\title{
Os discursos que aceitam a noção de esfera pública virtual
}

Há especialistas que aceitam, sem maiores restrições, a noção de esfera pública virtual, isto é, propõem que a internet funciona como um espaço efetivo e propício para a argumentação acerca da respublica (LÉVY, 2002; CASTELLS, 2001; SILVEIRA, 2000). A pluralidade de vozes e a possibilidade de combinação de "esferas públicas" (institucionais, temáticas, espontâneas, mediáticas) fariam com que a internet se tornasse apta a ser um ambiente discursivo por excelência. Conforme considera Castells:

\begin{abstract}
"Cyberspace has become a global electronic agora where the diversity of human disaffection explodes in a cacophony of accents. (...) the internet is not simply a technology: it is a communication medium (as the pubs were), and it is the material infrastructure of a given organizational form: the network (as the factory was). On both counts, the internet became the indispensable component of the kind of social movements emerging in the network society" (CASTELLS, 2001, p. 138-139).
\end{abstract}

Nestes termos, a discussão dos temas coletivos não estaria mais subsumida a uma lógica centrada no interesse dos partidos ou de organizações, mas este novo meio de comunicação poderia ser utilizado para devolver à esfera civil o poder de formulação da agenda pública.

Pierre Lévy destaca o espaço público virtual desterritorializado no sentido de permitir a participação dos interessados mesmo à distância, com autonomia para formar comunidades sobre os temas de seu agrado. Este espaço público ainda se alargaria pela não necessidade de mediadores de opinião, o que iria redefinir as condições de governança e estimular novas formas de fazer política e de formação cívica (LÉVY, 2002) ${ }^{12}$.

Do mesmo modo, para este autor, não se poderia ainda apontar como problema para o estabelecimento de uma esfera pública virtual a questão do acesso

\footnotetext{
12 Esta potencialidade de remissão da esfera pública é destacada por Pierre Lévy em pelo menos três oportunidades: "A nova esfera pública tem três características essenciais (...) a inclusão, a transparência e a universalidade. O ciberespaço é muito mais inclusivo do que todos os outros meios de comunicação anteriores. Ele permite a expressão pública a todos os indivíduos, grupos, instituições e comunidades, inclusive as comunidades (comunidades virtuais) não existentes anteriormente. (...) O ciberespaço (...) autoriza um grau de acesso à informação superior a tudo aquilo que se podia experimentar antes. Os internautas poderão se revelar cidadãos mais bem informados, politicamente mais ativos e socialmente mais conscientes do que os cidadãos off-line. (...) Os cibercidadãos expõem as idéias em seus websites e a prática do diálogo nas comunidades virtuais habituou-os à discussão, à deliberação pública. Sendo capazes de exprimir-se, eles esperam agora ser ouvidos. As novas formas de governança deverão encontrar lugar para essa 'nova raça de cidadãos', educados, informados, habituados a se exprimir (...)" (LÉVY, 2003, p. 375.376).
} 
restrito a essas tecnologias pela maioria da população, tendo em vista que, no século XVIII, a "idade de ouro" da esfera pública analisada por Habermas em seu Mudança estrutural da esfera pública, o acesso também era restrito aos "cidadãos", ou seja, apenas àqueles letrados, possuidores de bens materiais e aptos, de acordo com os ditames da época, a pensar a coisa pública ${ }^{13}$.

Keane (1996) vai empregar uma tipologia própria da noção de esfera pública para chegar a seu posicionamento sobre a relação entre o espaço da argumentação e as novas tecnologias de comunicação. Este autor considera que o termo esfera pública deve ser apreendido no plural, graças aos diferentes temas debatidos e às diferentes amplitudes que dada discussão pode alcançar. Deste modo, Keane realiza uma tipologia marcada por (1) micro esferas públicas, locais de encontros comunitários para o debate sobre temas coletivos (em um salão literário, por exemplo); (2) médio esferas públicas, que já alcançariam o nível do Estado-nação e seus milhões de interessados, através dos veículos de comunicação; e (3) macro esferas públicas (as disputas, na concepção de Keane, alcançariam bilhões de pessoas, em nível supranacional por causa da expansão das empresas de comunicação, que não mais se circunscrevem ao espaço nacional, e do avanço tecnológico, produzindo o que ele chama de "audiência mundial fictícia"). Às macro esferas públicas, para Keane, seriam adicionadas as redes telemáticas, onde os usuários não apenas buscam materiais de seu interesse, mas também procuram agir como cidadãos que se controvertem.

Na perspectiva de Marcondes Filho (2001), a internet funciona, sim, como esfera pública, mas tem sua referência inicial modificada na medida em que não implica o debate racional conforme a compreensão habermasiana. O destaque provido por Marcondes Filho se situa no fato de que a internet acrescenta às instituições (de governo, da imprensa), bem como ao próprio público, o caráter de öffentlichkeit, isto é, a abertura às vistas públicas das organizações e suas disposições.

Outros especialistas que dedicaram trabalhos para investigar a questão da esfera pública através das redes digitais foram Downey e Fenton (2003). Porém, estes trazem uma contribuição que se diferencia um pouco das anteriores, pois preferem empregar, em referência às redes digitais, o termo "contra-esfera-pública", e não "esfera pública autônoma". Esta contra-esfera provoca uma disputa com a esfera pública dominante (em vez de simples independência ou ruptura, característica atribuída ao espaço discursivo que carrega o adjetivo "autônomo"), ligada aos meios de comunicação de massa convencionais; isto é, a contra-esfera pública configura-se em oposição às argumentações colocadas nos espaços hegemônicos.

\footnotetext{
13 Pode-se perguntar: não seria uma contradição Lévy criticar a "idade de ouro" da esfera pública avaliada por Habermas ao mesmo tempo em que parece dar este mesmo tom de ouro à esfera pública virtual?
} 
Os meios digitais podem pôr em xeque esta esfera pública hegemônica ao permitirem outros tópicos de discussão.

Ao mesmo tempo em que tem o potencial de servir como ferramenta de mobilização, dizem Downey e Fenton, a internet pode, entretanto, alimentar formas de fragmentação social. Isto porque, não obstante a promessa de que a nova tecnologia de comunicação torna os cidadãos mais próximos geograficamente, ela comporta a capacidade de, do mesmo modo, levar seus usuários a diferentes direções, a buscar diferentes assuntos, favorecendo uma perspectiva individualista ${ }^{14}$.

Para Salter (2003), a esfera pública analisada por Habermas buscava a formação de uma vontade comum através do consenso, enquanto que a internet parece favorecer a fragmentação discursiva na medida em que dá vazão a uma grande quantidade de vozes. Em outros termos, diferenças inconciliáveis emergiriam do pluralismo possível, inviabilizando os processos de tomada de decisão em alguns momentos. Downey e Fenton avaliam, a partir desta suposição, que nem sempre estas situações de pluralidade são benéficas ${ }^{15}$ :

"Such networks obviously then become extremely problematic from the standpoint of discourse ethics. Greater pluralism may be regarded as a risk for deliberative democracy rather than its saviour. Such a concern is echoed by Sunstein (2001), who argues that the internet has spawned large numbers of radical websites and discussion groups allowing the public to bypass more moderate and balanced expressions of opinion in the mass media (which are also, he argues, subject to fragmentation for essentially technological reasons). Moreover, these sites tend to link only to sites that have similar views" (DOWNEY e FENTON, 2003, p. 189).

Um argumento final, de certa forma comum a boa parte dos autores acima citados, dá conta de que apenas a internet poderia realizar uma verdadeira esfera "pública", pois os outros meios de comunicação não permitem que todos os ângulos

\footnotetext{
${ }^{14}$ Como observa Papacharissi, em relação à formação de grupos de discussão na internet: "The number of people that our virtual opinions can reach may become more diverse, but may also become smaller as the internet becomes more fragmented. Special interest groups attract users who want to focus the discussion on certain topics, providing opportunities for specialized discussion with people who have a few things in common. As the virtual mass becomes subdivided into smaller and smaller discussion groups, the ideal of a public sphere that connects many people online eludes us. On the other hand, the creation of special interest groups fosters the development of several online publics, which, as Fraser noted, reflect the collective ideologies of their members" (PAPACHARISSI, 2002, p. 16-17).

15 Kakabadse, Kakabadse e Kouzmin (2003) adicionam mais uma consideração importante ao argumentar que, sem os modos institucionalizados de participação, seria difícil de agregar as preferências mais relevantes, podendo esta pluralidade excessiva resultar, inclusive, em uma paralisia do processo deliberativo institucionalizado no parlamento, em meio a tantas opiniões e vozes concorrentes.
} 
de um problema sejam colocados da maneira que cada ator bem desejar. Ou seja, o acesso a meios como a televisão, o jornal ou o rádio impresso, por serem de alto custo e exigirem uma estrutura pesada de funcionamento (maquinaria e pessoal capacitado), além de uma licença governamental, jamais poderiam ser tomados essencialmente como espaços "públicos".

\title{
Os discursos que negam o conceito de esfera pública virtual
}

Dean (2003), em sistematização semelhante à feita neste trabalho, identifica duas tendências de teóricos cuja preocupação é o funcionamento da internet como esfera pública: (a) os que não admitem a internet como esfera pública geralmente tomam o conceito normativo da categoria em questão e têm como principais queixas a exclusão digital (que impossibilita a participação de todos os interessados), a carência de racionalidade (um ambiente sem ordem discursiva, debate sobre temas de maneira pouco precisa) e de civilidade (a internet garante o anonimato que serviria para os usuários agredirem uns aos outros, por exemplo).

A outra corrente de especialistas (b) já considera que a internet é sim uma esfera pública, aliás, em excesso, como faz Esther Dyson:

\begin{abstract}
"Dyson's horror at the thought of 'all kinds of people' entering it tells us, first, that the possibility of an inclusive public sphere conjures up anxieties around truth and trust; and, second, that what she defends as the public sphere relies on a conception of rational debate that excludes all but the reasonable few. (...) Moreover, she suggests, in light of the underlying epistemology of the public sphere, that there is one truth and that there are experts out there who know this truth and who should be empowered to enlighten the rest of us. (...) So, for Dyson, the problem with the net is the very excesses that make it a public sphere - everyone is included: the ignorant, the ill-informed, the unauthorized. There is too much equality, too much inclusivity. Dyson's point boils down to the complaint that there are too many different opinions and ideas out there on the net" (DEAN, 2003, p. 99-100).
\end{abstract}

Depois de identificar estas posições extremas, a saída apontada por Dean é a de que a noção de internet como esfera pública é, antes de tudo, ideológica: as redes telemáticas serviriam para dar aos cidadãos a capacidade de discutir e trocar idéias, mas, na verdade, atuariam como uma camuflagem do que está por trás das transformações econômicas contemporâneas, como o capitalismo global, as trocas comerciais e a construção do que ela chama de tecnocultura. Tal conclusão, 
segundo Dean, faz com que a internet não possa ser tomada como neutra ou como apenas uma ferramenta a ser empregada dependendo da vontade de determinado agente:

\begin{abstract}
"New media present themselves for and as a democratic public. They present themselves for a democratic public in their eager offering of information, access, and opportunity. They present themselves as a democratic public when the very fact of networked communications comes to mean democratization, when expansions in the infrastructure of the information society are assumed to be enactments of a demos. But, as is becoming increasingly clear, the expansion and intensification of communication and entertainment networks yields not democracy but something else entirely-communicative capitalism. (...) Precisely those technologies that materialize a promise of full political access and inclusion drive an economic formation whose brutalities render democracy worthless for the majority of people" (DEAN, 2003, p. 102-103).
\end{abstract}

Dean alega aceitar o caráter normativo da esfera pública e, justamente esta aceitação, faz com que ela não considere a internet como legítimo espaço de discussão de qualidade: o ambiente digital é desorganizado; podem ser formados espaços, sim, mas que apenas indiretamente têm efetividade. Além disso, a autora acrescenta que a esfera pública deve possuir uma unidade que busque, sempre que possível, o consenso em torno dos temas coletivos. Isto também não ocorre na maioria das interações e debates travados em rede, pois a divergência, devido ao choque cultural e de visões de mundo, seria persistente (DEAN, 2003) ${ }^{16}$.

Deve-se questionar a autora sobre se tais dificuldades também não ocorrem nos espaços discursivos testemunhados já há algum tempo. Na verdade, a dissonância e a falta de unidade ocorrem nos mais diversos âmbitos coletivos, independentemente se digitais ou não. Se o mapeamento feito por Dean parece consistente, o mesmo não se pode dizer, todavia, de seu diagnóstico quanto à manipulação por um capitalismo global e de uma infiltração da tecnocultura.

Buchstein (1997) oferece pelo menos três razões para que a internet não seja tomada necessariamente como meio relacionado ao aperfeiçoamento da democracia: (1) a falta de competência dos cidadãos comuns para discutirem

\footnotetext{
16 Ainda de acordo com Dean, agora em um texto chamado Virtually citizens, de 1997, admitir a internet como "a" esfera pública, conforme sugestão de autores citados no tópico anterior, é pôr em segundo plano outros tipos de identidades, engajamentos e culturas populares que não empregam as redes de comunicação digitais. Hill e Hugues (1998) levam em consideração que não necessariamente a possibili. dade de interconexão entre usuários de diversas partes do planeta trará compreensão mútua, devido sobretudo aos diferentes quadros culturais de origem de cada um.
} 
temas que demandam conhecimento específico e capacidade de julgamento, não apenas político, mas para lidar com a própria tecnologia de comunicação; a conseqüência disso é o (2) acesso elitizado às potencialidades das redes telemáticas; por último, (3) a esfera pública teria sua natureza modificada a partir do momento em que não mais se dá face a face ${ }^{17}$.

Buchstein, de certa forma, concorda com a idéia de Wolton (2001) de que é necessário um compartilhamento de valores para, aí sim, se poder pensar em um aperfeiçoamento da democracia ${ }^{18}$. Isto é, a possibilidade do usuário poder consumir individualmente a informação que deseja graças à liberdade a que agora é submetido quando conectado, não adiciona grandes qualidades ao funcionamento da forma democrática de governo. Neste sentido, a internet também guarda o potencial de minar a cidadania na medida em que a comodidade oferece aos usuários julgamentos ligados apenas à sua existência privada (BUCHSTEIN, 1997). Adicionalmente, os autores mais céticos desacreditam a noção de que a formação da opinião pública se dê no mesmo nível nas agregações virtuais quando comparada às modalidades tradicionais $^{19}$.

Uma das perspectivas mais caras a esta discussão vem de Papacharissi (2002), que conduz sua reflexão a partir da distinção entre "espaço virtual" e "esfera virtual". Papacharissi propõe a apreensão da internet preferencialmente como um

17 Keane (1996) parece desacreditar a tese de que uma esfera pública teria sempre de agregar a característica de face a face para ser considerada genuína. Para ele, a internet e demais acontecimentos que geram discussões a nível planetário são provas de que o espaço simbólico de trocas e compartilha. mento de pontos de vista não necessariamente está ligado a um território qualquer: "A vida pública, alguém poderia dizer, está, no presente, sujeita a um processo de 'desterritorialização', o qual assegura que o sentimento de proximidade, compartilhado por cidadãos de diferentes milieux, leva cada vez menos a relacionamentos com os lugares em que eles nasceram de fato, onde eles cresceram, se apaixonaram, trabalharam, viveram, e onde eles irão eventualmente morrer" (KEANE, 1996, p. 25).

$18 \mathrm{E}$ para que tais valores vigorem, outros meios de comunicação e outros sentimentos de cunho comunitário são necessários: "The democratic ideal does not consist of merely one public sphere, but in order to have a democracy we must overlapping issues which we regard as being politically relevant. Or, to rephrase a famous formulation by John Rawls: democracies need 'overlapping discourses'. (...) This idea of universal data access is based on a highly questionable diagnosis of the weakness of modern democracies. It assumes that modern democracies suffer from a lack of information. One could argue, however, that the problem is that citizens and modern politics are hardly exhausting the information already pilled up. (...) I am not arguing that network surfing is a waste of time, sometimes it is exciting. My argument is that the credibility of information on the net gets lost as long as there are no substitutes for the traditional communication junctions" (BUCHSTEIN, 1997, p. 254).

19 Interessante a seguinte argumentação de Buchstein, que consolida sua aceitação da Internet como uma modalidade complementar para se obter informação: "If the net becomes the primary source of information, democracy will be deeply affected. The transformation of all information into saleable goods not only damages the egalitarian underpinnings of democracy, but also destroys the notion of a common public sphere. (...) not much empirical research has been collected on the alleged 'deliberative qualities' of political discourse on the net. The more or less impressionistic evidence currently at hand, however, does not support the paradise thesis at all" (BUCHSTEIN, 1997, p. 257). 
espaço virtual, mas ainda sem condições de aceder ao status de uma esfera pública virtual. Ou seja, introduz-se a idéia de que a internet funciona como um espaço com a capacidade de facilitar, mas não determinar, uma renovação da esfera pública:

"It should be clarified that a new public space is not synonymous with a new public sphere. As public space, the internet provides yet another forum for political deliberation. As public sphere, the internet could facilitate discussion that promotes a democratic exchange of ideas and opinions. $A$ virtual space enhances discussion; a virtual sphere enhances democracy (...) Despite the fact that the internet provides additional space for political discussion, it is still plagued by the inadequacies of our political system. It provides public space, but does not constitute a public sphere. (...) Our political experience online has shown that so far, the internet presents a public space, but does not yet constitute a public sphere" (PAPACHARISSI, 2002, p. 11-23).

No entender de Papacharissi, há uma extensão nos canais de comunicação a partir do advento do ciberespaço, sem, entretanto, poder ser constatada uma modificação substancial quanto à comunicação política em si. Ela argumenta, por exemplo, que as redes digitais demonstram, em muitos momentos, serem apropriadas pela política tradicional, em vez de revolucionar suas estruturas.

Uma outra contribuição de Papacharissi, de certo modo sustentada por Kinder (2002), se relaciona ao fato de que seria mais difícil a construção de laços de confiança e solidariedade através da internet, dada a carência de um encontro físico entre os usuários. Em outras palavras, critica-se, mais uma vez, a instabilidade das relações no plano digital, a carência de interações face a face, que seriam mais ricas do que as mediadas por equipamentos no que se refere à discussão da coisa pública ${ }^{20}$.

Dean (1997), ao contrário, argumenta que, apesar de serem mais ricas, as interações face a face não estão prontas a se despirem de preconceitos ou

\footnotetext{
20 Mostrando-se uma estrutura de comunicação que difere das tradicionais, a internet não permite o encontro físico, o que levanta alguns questionamentos sobre a estabilidade das interações, não obstante o desenvolvimento de tecnologias como a videoconferência. Os entes do discurso, entretanto, não podem fatalmente serem considerados "estranhos" entre si, ou seja, apesar de não se encontrarem face a face, os indivíduos podem aprofundar a discussão, voltar a se encontrar em outro dia, retomar o debate, criando, assim, maior intimidade. Segundo Mark Poster: "Now the question of 'talk', of meeting face-to-face, of 'public' discourse is confused and complicated by the electronic form of exchange of symbols. If 'public' discourse exist as pixels on screens generated at remote locations by individuals one has never and probably will never meet, as it is in the case of the internet with its 'virtual communities' and 'eletronics cafés', then how is it to be distinguished from 'private' letters, printface and so forth? The age of the public sphere as face-to-face talk is clearly over: the question of democracy must henceforth take into account new forms of electronically mediated discourse" (POSTER, 1997).
} 
permitirem que qualquer indivíduo se expresse à vontade: a tecnologia oferece, assim, proteções que devem ser levadas em consideração ${ }^{21}$.

\section{A esfera pública virtual como conversação civil}

O termo conversação civil foi apreciado por Umberto Eco, em seu livro Cinco escritos morais (1998), quando o autor, em referência ao desenvolvimento da televisão e dos modos de produção e difusão das informações advindas do campo político (tratando de fenômenos como adequação de linguagem dos programas partidários, telecomícios e discursos menos ideologizados), analisa brevemente os talk-shows norte-americanos do início dos anos 1970. Para Eco, estes foram espaços destinados a atrair os telespectadores de maneira não enfadonha (já evidenciando uma gramática que evitasse afastar a audiência), empregando entrevistas e disputas entre visões políticas divergentes. A conversação civil seria estimulada por este tipo de programa ao seduzir os cidadãos a conhecerem, pelo menos satisfatoriamente, matérias de natureza pública e política.

Paralelamente, levando-se em consideração a idéia de que debates informais e não-conclusivos podem ser considerados legitimamente esfera pública, aqui se procura identificar os espaços discursivos digitais com a noção de conversação civil, pois sua utilidade seria mais efetiva, no dizer de Hubertus Buchstein, ao nível da formação da opinião do que ao nível da tomada de decisões:

"Generally speaking, the internet is more useful on the level of opinionformation than on the level of decision-making. But even here, the technical attributes of the net set narrow limits. The internet is less applicable for the creation of new forms of democratic public spheres than for the support of already existing ones. In particular, the net allows for far easier access to documents, research statements, and other forms of factual information. (...) If we start with the normative premises that democracy contains elements of political deliberation, a distinction between private and public, and a public sphere which in principle can be shared by all citizens, the current reform strategies for computer democracy are more of a threat than a promise" (BUCHSTEIN, 1997, p. 260-261).

\footnotetext{
${ }^{21}$ Esta última ponderação é tema do livro Resisting the virtual life, de James Brook e lain A. Boal, para quem: "(...) virtual technologies are pernicious when their simulacra of relationships are deployed societywide as substitutes for face-to-face interactions, which are inherently richer than mediated interactions. Nowadays, the monosyllabic couch potato is joined by the information junkie in passive admiration of the little screen; this passivity is only refined and intensified by programmed 'interactivity'" (BROOK e BOAL apud DEAN, 1997, p. 268). Por outro lado, pode-se concordar com a posição de Dean (1997) de que encontro algum pode ser considerado puro, sem mediação.
} 
A conformação da esfera pública com fins decisórios necessita de uma ordem mínima de discussão, respeito mútuo e de uma pauta pré-estabelecida de assuntos a serem discutidos (características ressaltadas pela proposta de democracia deliberativa), o que parece pouco viável dada a amplitude e a dispersão típicas do ambiente digital. Em outras palavras, a modalidade de esfera pública virtual enquanto conversação civil parece ser a mais factível quando comparada às propostas de esfera pública virtual que se referem ao abrigo, decisão e implantação de políticas através do exercício do poder institucional.

Em vez de se buscar uma participação direta ou mesmo abrir mão das instituições representativas graças à possibilidade técnica ora oferecida, o correto, talvez, fosse estimular uma participação civil mais forte (mais uma vez, como requer a proposta de democracia deliberativa, herdeira, de certa forma, das perspectivas de strong democracy - defendidas por BARBER, 1984, ou PATEMAN, 1970), sendo os aspectos relativos à discussão e à informação dos atores envolvidos de relevância destacada.

Mas aqui é preciso que se faça uma distinção importante. Há momentos em que, sem dúvida, a internet se comporta como esfera pública eficaz, inclusive em termos deliberativos-decisórios. Todavia, geralmente, estes eventos ocorrem quando os grupos atingidos por esta deliberação, ao mesmo tempo em que são especializados ou dedicados a determinada temática, não são muito extensos. É o caso de uma lista de discussão.

Portanto, para tentar conferir maior lucidez à proposta, pode-se dizer que, no que se refere à política institucional de maior abrangência (aquela cujo objetivo é lidar com as administrações de municípios, estados e países), os debates empreendidos nas redes telemáticas funcionam melhor como reforço para os laços e espaços sociais já existentes, no sentido de abrir mais uma modalidade de comunicação que contribui para a formação discursiva da vontade.

A interação de caráter político mais próxima do ideal envolve o respeito ao outro com o objetivo de chegar a um consenso racional e aprovado pelo menos pela maioria. O problema é que um grande número das arenas de debate através de redes digitais não parece cumprir este preceito, essencial para se construir um resultado discursivo de qualidade (BOHMAN, 2004; GIMMLER, 2001; WILHELM, 2000). Nos fóruns abrigados pelo ambiente digital, são comuns ofensas ou exclusões de usuários que não se dobram a determinado posicionamento, o que na verdade não caracteriza uma atitude democrática, na medida em que se configura 
como uma forma de violência (como a expulsão dos pontos de vista discordantes em um canal de bate-papo, por exemplo) ${ }^{22}$.

À suposição de que a internet não é o melhor espaço para um debate racional se alia ainda o fato de que muitos dos casos de desentendimentos nas listas de discussão são gerados pelo envio repetido da mesma mensagem, anúncios do tipo classificados ou mesmo fofocas anônimas, o que pouco parece contribuir para um diálogo frutífero sobre temas coletivos (alguns destes entraves podem ser considerados ruídos de comunicação ${ }^{23}$.

\section{Conclusão}

Não se pode atribuir à internet a capacidade de, isoladamente, resolver os problemas que inquietam a forma democrática de governo e seus estudiosos. Possibilitar a reunião dos indivíduos para debater determinado tema não garante que todos queiram discutir, que a discussão se dê de modo frutífero e nem que o resultado da discussão consiga atingir as esferas representativas deliberativas, a quem foi concedido o poder de implantar os projetos públicos ${ }^{24}$. Desta forma, a internet não viria no sentido de prejudicar a democracia, mas também não seria responsável por uma revolução em termos de compreensão desta forma de governo.

O que se constata é que nem sempre todos os cidadãos possuem interesse na coisa pública. Como explica Dahl (2001), mesmo em uma assembléia popular ideal, assim como na maioria dos fóruns digitais, apesar de a palavra ser facultada a quem esteja presente (poder de voz), acontece com maior freqüência que poucos

\footnotetext{
22 De acordo com as contribuições de Buchstein, nesse sentido: "As the story goes, in the classical agora there was competition for the most reasonable way to solve a problem and the best way to build consensus. In the electronic agora, competition is for the most outrageous, provocative, and crazy point of view. This attitude attracts the creation and expression of extreme political actions. (...) Previously, newspaper readers followed arguments which were longer than what can appear on a computer screen. Electronic interviews tend to shorten and simplify complex issues. The process of typing encourages short and simple questions and equally concise replies. As Stoll puts it: 'Just as TV gives us soundbites, the online-interview provides one-line answers. (...) In digital reality, there is no space for glances, physical expressions, gestures, intonation, and overtones. Digital communication stress the exchange of pure data and allows participants to cut off unwelcome communication with just a move of a finger" (BUCHSTEIN, 1997, p. 258-259).

23 Miranda (1995) argumenta que, se por um lado o recurso a meios de comunicação como a Internet mostra os limites da palavra burocrática (aquela proferida apenas pelos "autorizados", ou seja, fontes governamentais e donos dos veículos de comunicação de massa), por outro as redes telemáticas de comunicação acabam por demonstrar o próprio limite da palavra, no sentido de que nem todo conteúdo propagado se torna útil para a formação da vontade política ou ao aperfeiçoamento da democracia.

24 Papacharissi (2002) concorda e, especulando sobre a efetividade dos discursos e debates oferecidos on-line, afirma que: "The power of the words and their ability to effect change, however, is limited in the current political spectrum. In a political system where the role of the public is limited, the effect of these online opinions on policy making is questionable" (PAPACHARISSI, 2002, p. 16).
} 
indivíduos argumentem por um período maior, em um jogo de réplicas e tréplicas, no intuito de convencer seus pares.

Se são diversas as ressalvas à internet enquanto esfera pública, por outro lado não se pode negar que muitos debates só se concretizam por causa do advento desta modalidade de comunicação. O ambiente digital pode ser tachado de caótico, dominado por empresas que visam apenas o lucro, pouco afeito à racionalidade, onde não se realiza debate de qualidade ou ainda que não é levado à sério pelas instâncias decisórias do sistema político. Mas a constatação que deve ser feita é a de que o debate racional entre cidadãos comuns, por exemplo, se não acontece na internet, também não parece acontecer rigorosamente fora dela. Em outros termos, deve-se considerar que, funcionando mal ou bem, pelo menos o ambiente digital abre a oportunidade para a exposição de opiniões e formação de arenas conversacionais, instâncias antes pouco prováveis ou mais difíceis de se realizarem.

O fato é que o modelo de esfera pública que exige dos cidadãos um engajamento e racionalidade constantes parece ser pouco correspondente à realidade social contemporânea. Há usuários que, por não se sentirem à vontade para se expor ou não considerarem ter qualificação suficiente, querem apenas aceder à informação, ter acesso ao material compartilhado por outros usuários mais ativos (como acontece com freqüência em listas de discussão) ${ }^{25}$. Dá-se um consumo privado do material lançado para o público, ou seja, em inúmeras ocasiões, as listas funcionam apenas como repositório de conteúdos, onde notícias e eventos são divulgados, sem gerarem maiores polêmicas ou, quando estas acontecem, geram apenas uma participação momentânea e restrita ${ }^{26}$. Mesmo na internet, os usuários não têm, em sua maioria, disponibilidade e dedicação completas para se engajarem em debates (PAPACHARISSI, 2002).

\footnotetext{
${ }^{25}$ Apesar de possibilitar a criação de novos espaços e a formação de agregações em torno de determinado interesse ou tema, se os cidadãos não tiverem um interesse pré-existente na coisa pública, nos assuntos de Estado, não é a internet quem vai criar esse empenho. De acordo com o que propõe Maia em relação à participação em listas e o debate realizado nestes espaços: "Não obstante, se haverá ou não o processo de debate é algo que não pode ser decidido a priori, pois o debate, em si mesmo, depende da livre motivação e da ação dos próprios interessados, que é contingencial e imprevisível. Além disso, o debate é mais do que uma mera pluralidade de vozes. Ele é focado e se caracteriza por discussões singulares. (...) Se todos falam e ninguém ouve, temos o resultado semelhante ao de uma torre de Babel. Conforme os estudos de Wilhelm (2000) e Hill e Hughes (1998) evidenciam, a grande maioria dos participantes em listas de discussão política e chats expressam a própria opinião, buscam e disponibilizam informação, sem que se vinculem a um debate propriamente dito" (MAIA, 2002a, p. 55-56).

26 Claro que há listas fechadas de especialistas em determinado assunto que podem funcionar mais ativamente, mas o que se procura traçar aqui é um diagnóstico panorâmico, ainda carente de maiores estudos empíricos rigorosos.
} 


\section{Referências Bibliográficas}

ALLAN, S. Mediating citizenship: online journalism and the public sphere new voices. Development, v. 46, n. 1, p. 30-40, 2003.

ANTOUN, H. A multidão e o futuro da democracia na cibercultura. Apresentado no XI Encontro Anual da Compós, Rio de Janeiro, 2002.

BARBER, B. Strong democracy: participatory politics for a new age. Berkeley: University of California Press, 1984.

BOHMAN, J. Public deliberation: pluralism, complexity and democracy. Cambridge, Mass.: MIT press, 1996.

Expanding dialogue: the internet, the public sphere and prospects for transnational democracy. The Sociological Review, v. 52, n. 1, p. 131-155, 2004.

BOUGNOUX, D. Introdução às ciências da comunicação. Bauru, SP: EDUSC, 1999.

BUCHSTEIN, H. Bytes that bite: the internet and deliberative democracy. Constellations, v. 4, n. 2, p. 248.263, 1997.

CALHOUN, C. (ed.). Habermas and the public sphere. Cambridge: The MIT Press, 1992.

CASTELLS, M. A sociedade em rede. São Paulo: Paz e Terra, 1999.

. The internet galaxy. Oxford University Press, 2001.

CEBRIÁN, J. L. A rede. São Paulo: Summus, 1999.

DAHL, R. A. Sobre a democracia. Brasília: Editora da Universidade de Brasília, 2001.

DEAN, J. Virtually citizens. Constellations, v. 4, n. 2, p. 264-282, 1997.

Why the net is not a public sphere. Constellations, v. 10, n. 1, p. 95-112, 2003. 
DOWNEY, J.; FENTON, N. New media, counter publicity and the public sphere. New Media \& Society, v. 5, n. 2, p. 185-202, 2003.

ECO, U. Cinco escritos morais. Rio de Janeiro: Record, 1998.

FERGUSON, M. Estratégias de governo eletrônico: o cenário internacional em movimento. In: EISENBERG, J.; CEPIK, M. (ed.). Internet e política: teoria e prática da democracia eletrônica.

Belo Horizonte: Editora UFMG, 2002.

GIMMLER, A. Deliberative democracy, the public sphere and the internet. Philosophy \& Social Criticism, v. 27, n. 4, p.21-39, 2001.

GOMES, W. Esfera pública política e media: com Habermas, contra Habermas. In: RUBIM, A.; BENTZ, I.; PINTO, M. (ed.). Produção e recepção dos sentidos mediáticos. Petrópolis: Vozes, 1998, p. $155 \cdot 185$.

Esfera pública política e media II. In: RUBIM, A.; BENTZ, I.; PINTO, M. (ed.). Práticas discursivas na cultura contemporânea. Porto Alegre: Unisinos, 1999, p. 203-231.

Opinião pública política hoje: uma investigação preliminar. In: FAUSTO NETO, A. et al. (ed.) Práticas mediáticas e espaço público. Porto Alegre: Editora da PUC/RS, 2001a, v. 1, p. 61-82.

Opinião política na internet: uma abordagem ética das questões relativas a censura e liberdade de expressão na comunicação em rede. Apresentado no X Encontro Anual da Compós, Brasília, 2001b.

Comunicação e cidadania: possibilidades e limites da ciberdemocracia. In: II IBÉRICO, 2004, Covilhã. Anais dos Congressos de Ciência da Comunicação. Covilhã: Universidade da Beira Interior, 2004.

GUIDI, L. Democracia eletrônica em Bolonha: a rede Iperbole e a construção de uma comunidade participativa on-line. In: EISENBERG, J.; CEPIK, M. (ed.). Internet e política: teoria e prática da democracia eletrônica. Belo Horizonte: Editora UFMG, 2002.

GUTMANN, A.; THOMPSON, D. Democracy and disagreement. Cambridge, Mass.: Belknap Press, 1996.

Disagreeing about deliberative democracy: reply to the critics. In: MACEDO, S. (ed.). Deliberative politics: essays on democracy and disagreement. New York: Oxford University Press, 1999. 
Why deliberative democracy?. Princeton: Princeton University Press, 2004.

HABERMAS, J. Mudança estrutural da esfera pública. Rio de Janeiro: Tempo Brasileiro, 1984.

. Direito e democracia: entre faticidade e validade. Rio de Janeiro: Tempo Brasileiro, 2003.

HILL, K. A.; HUGHES, J. E. Cyberpolitics: citizen activism in the age of the internet. New York: Rowman \& Littlefield, 1998.

KAKABADSE, A.; KAKABADSE, N. K.; KOUZMIN, A. Reinventing the democratic governance project through information technology? A growing agenda for debate. Public Administration Review, v. 63, n. 1, p. 44-60, 2003.

KEANE, J. Transformações estruturais da esfera pública. Comunicação \& Política, v. 3, n. 2, p. 6.29, 1996.

KINDER, T. Vote early, vote often? Tele-democracy in european cities. Public Administration, v. 80 , n. 3, p. 557-582, 2002.

LÉVY, P. A inteligência coletiva. São Paulo: Edições Loyola, 1998.

. Cyberdémocratie. Paris: Éditions Odile Jacob, 2002.

Pela ciberdemocracia. In: MORAES, D. (ed.). Por uma outra comunicação: mídia, mundialização cultural e poder. Rio de Janeiro: Record, 2003.

MAIA, R. Democracia e internet como esfera pública virtual: aproximando as condições do discurso e da deliberação. Apresentado no X Encontro Anual da Compós, Brasília, p. 46-60, 2001.

. Redes cívicas e internet: do ambiente informativo denso às condições da deliberação pública. In: EISENBERG, J.; CEPIK, M. (ed.). Internet e política: teoria e prática da democracia eletrônica. Belo Horizonte: Editora UFMG, 2002a.

Democracia e internet como esfera pública virtual: aproximando as condições do discurso e da deliberação. In: MOTTA, L. G. (ed.). Estratégias e culturas da comunicação. Brasília: Editora da UnB, 2002b, p. 107-128. 
MARCONDES FILHO, C. Haverá vida após a internet?. Revista Famecos, Porto Alegre, n. 16, dez. 2001.

MIRANDA, J. B. Espaço público, política e mediação. Revista de Comunicação e Linguagens, v. 21-22, p. 129.148, 1995.

MITRA, A. Marginal voices in cyberspace. New Media \& Society, v. 3, n. 1, p. 29-48, 2001.

MORAES, D. O concreto e o virtual. Rio de Janeiro: DP\&A, 2001.

PAPACHARISSI, Z. The virtual sphere: the internet as a public sphere. New Media \& Society, v. 4, n. 1, p. 9-27, 2002.

PATEMAN, C. Participation and democratic theory. Cambridge: Cambridge University Press, 1970.

POSTER, M. Cyberdemocracy: internet and the public sphere. In: PORTER, D. (ed.). Internet culture. New York: Routledge, 1997, p. 201-218.

Cidadania, mídia digital e globalização. In: MORAES, D. (org.). Por uma outra comunicação: mídia, mundialização cultural e poder. Rio de Janeiro: Record, 2003.

SALTER, L. Democracy, new social movements and the internet: a habermasian analysis. In: MCCAUGHEY, M.; AYERS, M. D. (ed.). Cyberactivism: online activism in theory and practice. New York, Routledge, 2003, p. 117-144.

SILVEIRA, S. A. O novo desafio da democracia na sociedade da informação. Anuário de Jornalismo, São Paulo, v. 1, n. 1, 2000.

WILHELM, A. Democracy in the digital age: challenges to political life in cyberspace. New York: Routledge, 2000.

WOLTON, D. E depois da internet? Para uma teoria crítica dos novos medias. Algés, Portugal: Difel, 2001. 